\title{
Self-esteem, stress and self-rated health in family planning clinic patients
}

\author{
James E Rohrer*1 and Rodney Young ${ }^{2}$
}

Address: ${ }^{1}$ Department of Family and Community Medicine, Texas Tech University Health Sciences Center, USA and ${ }^{2}$ Department of Family Medicine, Texas Tech University Health Sciences Center-Amarillo, USA

Email: James E Rohrer* - james.rohrer@ttuhsc.edu; Rodney Young -rodney.young@ttuhsc.edu

* Corresponding author

Published: 03 June 2004

BMC Family Practice 2004, 5:I I
Received: 01 March 2004

Accepted: 03 June 2004

This article is available from: http://www.biomedcentral.com/I47I-2296/5/II

(c) 2004 Rohrer and Young; licensee BioMed Central Ltd. This is an Open Access article: verbatim copying and redistribution of this article are permitted in all media for any purpose, provided this notice is preserved along with the article's original URL.

\begin{abstract}
Background: The independent effects of stress on the health of primary care patients might be different for different types of clinic populations. This study examines these relationships in a lowincome female population of patients attending a family planning clinic.
\end{abstract}

Methods: This study investigated the relevance of different sources of personal stress and social support to self-rated health, adjusting for mental health, health behavior and demographic characteristics of subjects. Five hundred women who attended family planning clinics were surveyed and 345 completed the form for a response rate of 72 percent.

Results: Multiple logistic regression analysis revealed that liking oneself was related to good selfrated health (Odds ratio $\mathbf{7 . 1} \mathrm{I}$ ), but stress or support from children, parents, friends, churches or spouses were not significant. White non-Hispanic and non-white non-Hispanic respondents had lower odds of reporting good self-rated health than Hispanic respondents (odds ratios were 2.87 and 2.8I, respectively). Exercising five or more days per week also was related to good self-rated health. Smoking 20 or more cigarettes per day, and obese III were negatively related to good selfrated health (odds ratios were .19 and .22, respectively with corresponding $\mathrm{P}$-values equal to .0043 and .0332).

Conclusions: Among younger low-income women, addressing low self-esteem might improve health status.

\section{Background}

Many variables influence self-rated health, including mental health, lifestyle (exercise, diet, smoking), psychosocial stressors (e.g., work strain and life stress) [1-6] depression, social supports [7], physical stressors (physical demands at work), pain, [8] coping skills, income and inequality $[9,10]$, job insecurity $[11,12]$, and housing quality [2]. The relative importance of these risk factors can be expected to differ from one population to another.
The importance of lifestyle as a determinant of health status is supported by voluminous research reports $[13,14]$. Stress as a risk factor for poor health has been examined less frequently in population studies. Recent populationbased research has demonstrated an association between living in an unsafe neighborhood and poor self-rated health, further supporting the theory that stress influences population health [14]. 
However, stress can come from many different sources. The social context we live in is one example, but the personal circumstances experienced by individuals might be expected to have a more direct effect on health status. After all, when conflict arises within a family, the psychological consequences can be dramatic. Even though the relevance of personal stressors to self-rated health has not previously been examined in the community health literature, its importance is not seriously in doubt. Of greater interest is whether different sources of personal stress will be important to health status in a community sample. For example, is having a stressful spouse a more important risk factor for poor health than having a stressful child?

The purpose of the study reported here was to investigate the importance of personal stressors in determining selfrated health. The sample was drawn from a low-income female population: women using a family planning clinic for primary care. Health behavior and other personal characteristics were measured and held constant in order to determine the independent effect of different sources of personal stress on self-rated health.

\section{Methods}

The study reported here was a cross-sectional survey of primary care patients attending one of five Planned Parenthood clinics in the Panhandle of Texas. Planned Parenthood in this area provides basic primary care and family planning to low-income women. This includes screening for sexually transmitted diseases, gynecologic cancers and birth control. Abortions are not provided at these clinics.

Eligibility for the study was limited to patients who were over age 18 and not pregnant. The study was granted exempt status by the Amarillo Institutional Review Board. Data were collected in the Planned Parenthood clinics (one urban and four small rural) in the Texas Panhandle. Questionnaires were placed on a table in waiting areas, with a poster inviting participation. Clinic staff also distributed survey forms. Subjects placed the completed forms in a sealed box. No protected health information was collected. Sealed boxes containing survey forms were returned to Texas Tech for data entry. Microsoft Access was used for data entry.

Five hundred forms were distributed. Twenty were returned by ineligible persons and were excluded from the sample. The final data set was comprised of forms returned by 345 eligible subjects. Computing the response rate as completed returns divided by eligibles $(345 /(500-$ $20)$ produces a participation rate of .719 .

\section{Measures}

The dependent variable was overall self-rated health. Independent variables were age, race, ethnicity, education, obesity, exercise, social support, stress, self-esteem, anxiety, and depression. Key instruments are discussed below.

\section{Duke Health Profile (The DUKE)}

Health items were taken from the Duke Health Profile, which was developed by family medicine faculty at Duke University. The DUKE is a 17-item scale that addresses physical, mental and social health [15]. Self-rated health was measured using the following item: "I am basically a healthy person." Possible responses were "Yes, describes me exactly", "Somewhat describes me," or "No, doesn't describe me at all." The first response measured "healthy" while the latter two responses were combined to form "not healthy". This resulted in 35.9 percent in the 'not healthy' group and 64.1 percent in the 'healthy' group. Mental health was measured in terms of self-esteem ("I like who I am"), family relationships ("I am happy with my family relationships"), sociability ("I am comfortable being around people"), feeling depressed or sad, and nervousness. Possible responses for all of the mental health items "Yes, describes me exactly", "Somewhat describes me," or "No, doesn't describe me at all." Social health was measured in terms of socializing with other people (talking or visiting with friends or relatives) and taking part in social, religious, or recreational activities (meetings, church, movies, sports, parties). Possible responses were None, Some, and A Lot. Liking oneself was recoded by combining the negative response with "Somewhat", because only four subjects said "No, doesn't describe me at all."

\section{Duke Social Support and Stress Scale (DUSOCS)}

Stress and social support items were taken from the DUSOCS. The DUSOCS contains items addressing personal support and personal stress [16]. In this study, respondents were asked how supportive spouses, parents, children, friends, and churches were. In regard to stress, a person who stresses the respondent is defined as one who causes problems or makes life more difficult [16]. Respondents were asked how much they are stressed by spouses, parents and children. Possible responses were None, Some, A Lot, and There is No Such Person. Friend support was recoding by combining "None" with "Some" because only three reporting having no friends.

\section{Health behavior}

Cigarette smoking, exercise and body mass index were used to measure health behavior. Cigarette smoking per day was categorized as None, 1-9, 10-19, or 20 or more. Exercise was measured in terms of times per week (none, one day, two days, three days, four days, more than four). 
Table I: Descriptive statistics: demographic variables

\begin{tabular}{|c|c|c|c|c|c|}
\hline Variable & Total pct & Healthy (\%) & Not healthy (\%) & $N$ & $P$ \\
\hline City limits & & & & 327 & 0.4650 \\
\hline No & 13.1 & 69.8 & 30.2 & & \\
\hline Yes & 86.9 & 62.7 & 37.3 & & \\
\hline Age category & & & & 345 & 0.5731 \\
\hline Low $(<2 I)$ & 18.6 & 64.1 & 35.9 & & \\
\hline Medium $(2 \mid-30)$ & 56.5 & 62.1 & 37.9 & & \\
\hline High $(>30)$ & 24.9 & 68.6 & 31.4 & & \\
\hline Number in home & & & & 345 & 0.3471 \\
\hline None & 12.8 & 72.7 & 27.3 & & \\
\hline One & 24.3 & 64.3 & 35.7 & & \\
\hline Two to three & 45.2 & 64.7 & 35.3 & & \\
\hline Four or more & 17.7 & 55.7 & 44.3 & & \\
\hline Education & & & & 345 & 0.3633 \\
\hline Less than high school & 11.3 & 56.4 & 43.6 & & \\
\hline High school degree or equivalent & 28.4 & 61.2 & 38.8 & & \\
\hline More than high school & 60.3 & 66.8 & 33.2 & & \\
\hline Ethnicity/Race & & & & 345 & 0.059 \\
\hline Hispanic & 28.7 & 54.5 & 45.5 & & \\
\hline White non-Hispanic & 56.5 & 67.2 & 32.8 & & \\
\hline Other & 14.8 & 70.6 & 29.4 & & \\
\hline
\end{tabular}

Body mass index (BMI) was computed as weight in pounds times 703 divided by height in inches squared. Healthy weight was BMI between 18.5 and 24.9. BMI between 25 and 30 was overweight. BMI between 30 and 35 was Obesity Class I. Obesity Class II was BMI between 35 and 40 . BMIs over or equal to 40 were Obesity Class III.

\section{Demographics}

Age, number of persons in the home, race/ethnicity (nonHispanic white, Hispanic, other), rural vs urban (inside the city limits vs outside), and educational level (less than high school, high school or equivalent, more than high school) were used to control for demographic differences among subjects. The median age was 25 . Age was categorized as low (18-21), medium (21-30) or high (31 or over). Breaks in the age distribution were made at the first and third quartile.

\section{Statistical analysis}

Chi-square tests were used to test for the relationship between each independent variable and self-rated health. Variables that were significant at $\mathrm{p}<.15$ were included in a multiple logistic regression analysis. The multiple logistic regression model was reduced in a backwards stepwise fashion: the variable with the highest p-value was dropped, the model was re-estimated, then the variable with the highest p-value was dropped, until all variables in the model were significant at $\mathrm{p}<.05$. EpiInfo 3.2 was used for data analysis.

\section{Results}

The sample was comprised of relatively young women, with only 18.6 percent over the age of 30 (see Table 1). Over 86 percent lived within city limits. Most respondents lived with two or three other people. Over 60 percent had high school degrees. Almost 29 percent were Hispanic and over 56 percent were non-Hispanic White. Health status did not differ significantly for any of these variables, except Hispanic ethnicity $(p=.0270)$.

Less than half of respondents reported experiencing some or a lot of stress from children, parents, or spouses (Table 2 ). Of these three variables, only child stress met the selection criterion for inclusion in the logistic regression model. Most respondents reported receiving a lot or some support from children, parents, spouses, or friends. Church support was received somewhat less frequently. None of the support variables was retained for inclusion in the multivariate model.

Other mental health variables are shown in Table 3. Nearly 70 percent reported that they liked themselves. Over 62 percent said their families were happy. Over 70 percent said they were comfortable around people. 'Some' or 'a lot; of nervousness was reported by over 37 percent of respondents, while over 42 percent said they were depressed 'some' or 'a lot'. Socializing with friends 'a lot' was reported by over 64 percent and over 76 percent engaged in social activities such as church 'some' or 'a lot' of the time. All of these variables were retained for use in 
Table 2: Descriptive statistics (stress and social support)

\begin{tabular}{|c|c|c|c|c|c|}
\hline Variable & Total pct & Healthy (\%) & Not healthy (\%) & $\mathbf{N}$ & $\mathbf{p}$ \\
\hline Self-rated health & 100 & 64.1 & 35.9 & 345 & \\
\hline Child stress & & & & 345 & 0.0523 \\
\hline A lot & 6.4 & 40.9 & 59.1 & & \\
\hline Some & 30.7 & 61.3 & 38.7 & & \\
\hline None & 31.9 & 70.9 & 29.1 & & \\
\hline No such person & 31 & 64.5 & 35.5 & & \\
\hline Parent stress & & & & 345 & 0.227 \\
\hline A lot & 9 & 58.1 & 41.9 & & \\
\hline Some & 35.1 & 58.7 & 41.3 & & \\
\hline None & 50.7 & 67.4 & 32.6 & & \\
\hline No such person & 5.2 & 77.8 & 22.2 & & \\
\hline Spouse stress & & & & 345 & 0.1844 \\
\hline A lot & 13.9 & 54.2 & 45.8 & & \\
\hline Some & 30.1 & 62.5 & 37.5 & & \\
\hline None & 39.1 & 70.4 & 29.6 & & \\
\hline No such person & 16.8 & 60.3 & 39.7 & & \\
\hline Child support & & & & 345 & 0.459 \\
\hline A lot & 36.8 & 64.6 & 35.4 & & \\
\hline Some & 19.7 & 57.4 & 42.6 & & \\
\hline None & 11.6 & 72.5 & 27.5 & & \\
\hline No such person & 31.9 & 64.5 & 35.5 & & \\
\hline Parent support & & & & 345 & 0.8621 \\
\hline A lot & 51 & 64.8 & 35.2 & & \\
\hline Some & 29.9 & 61.2 & 38.8 & & \\
\hline None & 13.3 & 65.2 & 34.8 & & \\
\hline No such person & 5.8 & 70 & 30 & & \\
\hline Spouse support & & & & 345 & 0.6085 \\
\hline A lot & 49.9 & 61.6 & 38.4 & & \\
\hline Some & 21.2 & 67.1 & 32.9 & & \\
\hline None & 12.2 & 71.4 & 28.6 & & \\
\hline No such person & 16.8 & 62.1 & 37.9 & & \\
\hline Church support & & & & 345 & 0.4892 \\
\hline A lot & 25.8 & 69.7 & 30.3 & & \\
\hline Some & 24.9 & 62.8 & 37.2 & & \\
\hline None & 27.8 & 64.6 & 35.4 & & \\
\hline No such person & 21.4 & 58.1 & 41.9 & & \\
\hline Friend support & & & & 345 & 0.2924 \\
\hline A lot & 51.9 & 65.9 & 34.1 & & \\
\hline Some & 34.5 & 58.8 & 41.2 & & \\
\hline None & 13.6 & 70.2 & 29.8 & & \\
\hline
\end{tabular}

the multivariate model except the two relating to social life.

Only about 65 percent of the group was non-smokers; nearly seven percent smoked 20 or more cigarettes per day (Table 4). Over 40 percent got no exercise at all. Only 45.2 percent were at healthy body weights. Over 20 percent were obese.

Variables that were significant at $\mathrm{p}<.15$ were included in the multiple logistic regression model, then variables with the highest p-values were deleted stepwise. The final model is shown in Table 5. Women who said they liked themselves were much more likely to report good health $(\mathrm{OR}=7.1)$. Non-Hispanic White and non-white non-Hispanic women were more likely to report good health than Hispanic women (ORs were 2.81 and 2.87, respectively). Cigarette smoking was not related to self-reported health, except for those women who smoked 20 or more cigarettes each day; these heavy smokers had lower odds of reporting good health than persons who did not smoke at all $(\mathrm{OR}=.19, \mathrm{p}=.0043)$. Exercise was not related to self-rated health unless a one-tailed test was used. Respondents who exercised only day per week were less likely to report good health than persons who exercised at least five days per week $(\mathrm{OR}=.7233, \mathrm{p}=.0919)$. Obesity 
Table 3: Descriptive statistics: other mental health variables

\begin{tabular}{|c|c|c|c|c|c|}
\hline Variable & Total pct & Healthy (\%) & Not healthy (\%) & $\mathbf{N}$ & $\mathbf{p}$ \\
\hline Like myself & & & & 343 & 0.0000 \\
\hline Somewhat & 32.1 & 35.5 & 64.5 & & \\
\hline Yes & 67.9 & 77.3 & 22.7 & & \\
\hline Happy family & & & & 328 & 0.0034 \\
\hline No & 4.6 & 53.3 & 46.7 & & \\
\hline Somewhat & 32.9 & 50.9 & 49.1 & & \\
\hline Yes & 62.5 & 69.8 & 30.2 & & \\
\hline Comfortable around people & & & & 332 & 0.0428 \\
\hline No & 3.9 & 61.5 & 38.5 & & \\
\hline Somewhat & 23.2 & 50.6 & 49.4 & & \\
\hline Yes & 72.9 & 66.5 & 33.5 & & \\
\hline Nervous & & & & 334 & 0.0934 \\
\hline A lot & 7.5 & 44 & 56 & & \\
\hline Some & 29.9 & 62 & 38 & & \\
\hline None & 62.6 & 66 & 34 & & \\
\hline Depressed & & & & 336 & 0.0003 \\
\hline A lot & 9.8 & 39.4 & 60.6 & & \\
\hline Some & 32.7 & 56.4 & 43.6 & & \\
\hline None & 57.4 & 71.5 & 28.5 & & \\
\hline Socialize & & & & 344 & 0.2444 \\
\hline A lot & 64.5 & 63.1 & 36.9 & & \\
\hline Some & 29.4 & 62.4 & 37.6 & & \\
\hline None & 6.1 & 81 & 19 & & \\
\hline Social activities & & & & 341 & 0.3133 \\
\hline A lot & 30.5 & 69.2 & 30.8 & & \\
\hline Some & 46.9 & 60 & 40 & & \\
\hline None & 22.6 & 63.6 & 36.4 & & \\
\hline
\end{tabular}

was related to worse self-rated health (OR for Obese III = $.22(\mathrm{p}=.0332)$, OR for Obese $\mathrm{I}=.49(\mathrm{p}=.0755))$.

\section{Discussion}

The various sources of personal stress and social support studied here were not significantly related to self-rated health. We could not demonstrate a direct relationship with self-rated health in this relatively young, female population after adjustment for other variables. However, personal stress and social support may have indirect effects on self-rated health, an issue not investigated in this study.

The mental health variables studied, with the exception of self-esteem, were not significantly related to self-rated health in the multivariate model, though several were significant in two-way tables. We found that self-esteem, as measured by whether or not a woman likes herself, is an important indicator of self-rated health. Liking oneself was significant even after controlling for ethnicity and health behavior. Poor health could be the cause of poor self-esteem, or the reverse may be true. Though our study was cross-sectional in design and does not prove causal relationships, this appears to be an important variable in young women that deserves further research.

Among the health behavior variables, BMI was significantly related to better self-reported health (using a onetailed test). Having a BMI in the obese range was significant, but a BMI in the overweight range was not. Heavy smoking was significantly related to poor health, but light smoking was not. Exercise was only weakly related to selfrated health. These findings may be due to the relative youthfulness of the sample population. Over a lifetime, self-rated health can be expected to decline among persons with unhealthy lifestyles. Since patients are frequently unwilling or unable to comply with physician directives to lose enough weight to arrive at a BMI in the healthy range, or quit smoking altogether, one might argue that, from a harm-reduction standpoint, moderation in both smoking and body weight are to be encouraged. Though clearly not as beneficial to overall health as attaining ideal body weight or stopping smoking completely, our findings suggest that helping patients moderate these behaviors may yield significant improvement in self-rated health. 
Table 4: Descriptive statistics: healthy behavior variables

\begin{tabular}{|c|c|c|c|c|c|}
\hline Variable & Total pct & Healthy (\%) & Not healthy (\%) & $\mathbf{N}$ & $\mathbf{p}$ \\
\hline Cigarette smoking & & & & 345 & 0.0005 \\
\hline None & 64.9 & 69.6 & 30.4 & & \\
\hline One to nine & 15.1 & 65.4 & 34.6 & & \\
\hline Ten to 19 & 10.1 & 51.4 & 48.6 & & \\
\hline Twenty or more & 6.7 & 26.1 & 73.9 & & \\
\hline Refused & 3.2 & 63.6 & 36.4 & & \\
\hline Exercise & & & & 345 & 0.044 \\
\hline None & 42.3 & 58.2 & 41.8 & & \\
\hline One day & 10.7 & 51.4 & 48.6 & & \\
\hline Two days & 17.1 & 69.5 & 30.5 & & \\
\hline Three days & 15.7 & 68.5 & 31.5 & & \\
\hline Four days & 7 & 83.3 & 16.7 & & \\
\hline Five or more & 7.2 & 76 & 24 & & \\
\hline$B M I$ & & & & 345 & 0.008 \\
\hline Underweight & 2.9 & 70 & 30 & & \\
\hline Healthy & 45.2 & 69.9 & 30.1 & & \\
\hline Overweight & 30.4 & 67.6 & 32.4 & & \\
\hline Obese I & 13 & 46.7 & 53.3 & & \\
\hline Obese II & 4.6 & 56.2 & 43.8 & & \\
\hline Obese III & 3.8 & 30.8 & 69.2 & & \\
\hline
\end{tabular}

Our findings differ from other reports [14] in that we did not find social activity to be related to self-rated health. While social isolation can be regarded as an important risk factor, it occurred infrequently in our sample. These results serve to make an important point: the determinants of self-rated health can be expected to differ for different types of populations. The relatively young and socially active group we studied was more adversely affected by poor self-esteem than it was by social isolation. We also suspect that stress and social support might be important in other groups than it is among younger women.

There are some limitations to this study that should be considered. Since the study was cross-sectional in design, using a convenience sample, the findings may not be representative of the population from which it was drawn, and causal relationships cannot be established. Furthermore, the study population was predominantly composed of young, low-income females, which may limit the generalizability of these findings.

Another limitation of the study is that it does not address work-related stress. Worklife stresses repeatedly have been shown to influence the health of employees [3,4]. Gender differences have been demonstrated in relation to this phenomenon $[4,17,18]$. For example, the Catalonian Health Survey conducted in Spain in 1994 revealed female manual workers to have worse self-rated health than their male peers [18]. Analysis of the Canadian
National Population Health Survey showed that psychosocial determinants of health were more important for women than for men [17]. This project did not conclude analyses of work stress because many of our subjects were unemployed. Therefore, our findings may not be generalizable to employed populations. On the other hand, in a Norwegian study of nurses aides, almost all of whom were female, work factors had little impact on sickness absence [5]. We might hypothesize that family is more important than work in some populations, and thus family stress might be more damaging than job stress. Further investigation of the relative importance of family stress, job stress, and self esteem in distinctly different populations is needed.

Nevertheless, the size of the sample is adequate, the participation rate was good, and the hypotheses tested were innovative. Therefore, the results are important to epidemiologists and others who study the determinants of selfrated health in the community.

\section{Conclusions}

The research question for this paper was about the determinants of self-rated health in a low-income female population in a single community. Our study differs from some other studies of self-rated health by its inclusion of several types of personal stress and social support as well a variety of mental health measures. By adjusting for exercise levels, body weight and cigarette smoking we were able to show that personal stress and social support were 
Table 5: Unconditional logistic regression of self-rated health $(-2 * L L=349.5383, p<.0000, N=342)$

\begin{tabular}{|c|c|c|c|}
\hline Variable & Odds ratio & Confidence interval & $P$ \\
\hline \multicolumn{4}{|l|}{ Like myself } \\
\hline Somewhat & I & & \\
\hline Yes & 7.1131 & $3.994 \mid-12.6678$ & 0.0000 \\
\hline \multicolumn{4}{|l|}{ Ethnicity/Race } \\
\hline Hispanic & 1 & & \\
\hline White, non-Hispanic & 2.8748 & $1.5667-5.2750$ & 0.0007 \\
\hline Other & 2.8098 & $1.1973-6.5937$ & 0.0176 \\
\hline \multicolumn{4}{|l|}{ Cigarette Smoking } \\
\hline None & 1 & & \\
\hline One to nine & 0.9787 & $0.4709-2.0338$ & 0.9539 \\
\hline Ten to nineteen & 0.5368 & $0.2295-1.2555$ & 0.1513 \\
\hline Twenty or more & 0.1922 & $0.0620-0.5960$ & 0.0043 \\
\hline Refused & 0.8601 & $0.1842-4.0154$ & 0.8479 \\
\hline \multicolumn{4}{|l|}{ Exercise } \\
\hline Five or more & I & & \\
\hline None & 0.7236 & $0.2376-2.2036$ & 0.5691 \\
\hline One day & 0.3364 & $0.0947-1.1942$ & 0.0919 \\
\hline Two days & 0.9371 & $0.2799-3.1379$ & 0.9162 \\
\hline Three days & 0.7193 & $0.2116-2.445 \mid$ & 0.5977 \\
\hline Four days & 2.4926 & $0.5211-11.9223$ & 0.2527 \\
\hline \multicolumn{4}{|l|}{ Body weight } \\
\hline Healthy & 1 & & \\
\hline Underweight & $0.984 I$ & $0.1795-5.3964$ & 0.9853 \\
\hline Overweight & 1.0317 & $0.5498-1.9357$ & 0.9227 \\
\hline Obese I & 0.4909 & $0.2240-1.0758$ & 0.0755 \\
\hline Obese II & 0.6815 & $0.1936-2.3996$ & 0.5505 \\
\hline Obese III & 0.2161 & $0.0528-0.8850$ & 0.0332 \\
\hline Constant & 0.2225 & & \\
\hline
\end{tabular}

not important, as were most of our mental health measures. Because we found that liking oneself was significant, this study sheds new light on the determinants of selfrated health.

Overall mental health obviously is related to overall health. However, overall all mental health can be broken down into multiple dimensions. In this study, mental health was measured with five variables: self-esteem ("I like who I am"), family relationships ("I am happy with my family relationships"), sociability ("I am comfortable being around people"), feeling depressed or sad, and nervousness. These represent five different aspects of mental health. Only one of these five was retained for use in the final model (self-esteem) and it remained statistically significant. We do not interpret this as meaning that mental health in general is related to overall health (this indeed would not be new information) but instead are pointing out that a single item addressing self-esteem is related to physical health. Using different measures, a Canadian national survey revealed that self-esteem was related to better health, which supports our findings [13].
These findings have significance for clinical practice. Clinicians may want to ask their patients if they like themselves. Health education programs intended to build selfesteem among low-income women are indicated. Programs such as these may be at least as important as programs directed at smoking cessation, stimulation physical activity, and weight control. In fact, our data indicate that reduced smoking (a 'harm reduction' strategy) might make a smoker feel as healthy as quitting altogether, at least for a few years. Similarly, the focus of weight control programs perhaps should be shifted to obesity prevention, since being in the overweight category is a reasonable 'harm reduction' strategy for persons who are at risk of becoming obese.

\section{Competing interests}

None declared.

\section{Authors' contributions}

JR planned the study, organized the survey, and wrote the first draft of the result. RY revised the manuscript. 


\section{Acknowledgements}

This study was partially supported by the Women's Health and Research Institute of Amarillo. Tanya Fraley organized data collection and data management. The support and cooperation of Planned Parenthood in Amarillo was vital to the success of the project. Dr. Rush Pierce provided a useful review of the first draft.

\section{References}

I. Ostry AS, Barroetavena M, Hershler R, Kelly S, Demers PA, Teschke $\mathrm{K}$, Hertzman D: Effect of de-industrialization on working conditions and self reported health in a sample of manufacturing workers. J Epidemiol Community Health 2002, 56:506-509.

2. Dunn JR: Housing and inequalities in health: a study of socioeconomic dimensions of housing and self reported health from a survey of Vancouver residents. I Epidemiol Community Health 2002, 56:67I-68I.

3. Pikhart H, Bobak M, Siegrist J, Pajak A, Rywik S, Kyshegyi J, Gostatas A, Skodova Z, Marmot M: Psychosocial work characteristics and self rated health in four post-communist countries. J Epidemiol Community Health 200I, 55:624-630.

4. Ala-Mursula L, Vahtera J, Kivimaki M, Kevin MV, Pentti J: Employee control over working times: associations with subjective health and sickness absences. J Epidemiol Community Health 2002, 56:272-278

5. Eriksen W, Bruusgaard D, Knaardahl S: Work factors as predictors of sickness absence: a three month prospective study of nurses' aides. Occup Environ Med 2003, 60:271-278.

6. Parkerson GR, Broadhead WE, Tse CK: Perceived family stress as a predictor of health-related outcomes. Arch Fam Med 1995, 4:253-260

7. Zunzunegui MV, Beland F, Ortero A: Support from children, living arrangements, self-rated health and depressive symptoms of older people in Spain. International Journal of Epidemiology 2001, 30:1090-1099.

8. Molarius A, Janson S: Self-rated health, chronic diseases, and symptoms among middle-aged and elderly men and women. Journal of Clinical Epidemiology 2002, 55:364-370.

9. Rahkonen O, Lahelma E, Martikainen P, Silventoinen K: Determinants of health inequalities by income from the 1980s to the I 990s in Finland. J Epidemiol Community Health 2002, 56:442-443.

10. Weich S, Lewis G, Jenkins SP: Income inequality and self rated health in Britain. J Epidemiol Community Health 2002, 56:436-44I.

I I. Ferrie JE, Shipley MJ, Stanfeld SA, Marmot MG: Effects of chronic job insecurity and change in job security on self reported health, minor psychiatric morbidity, physiological measures, and health related behaviours in British civil servants: the Whitehall II study. J Epidemiol Community Health 2002, 56:450-454.

12. Virtanen P, Vahtera J, Kivimaki M, Pentti J, Ferrie J: Employment security and health. I Epidemiol Community Health 2002, 56:569-574.

13. Cott CA, Gignac MAM, Badley EM: Determinants of self rated health for Candadians with chronic disease and disability. J Epidemiol Community Health 1999, 53:731-736.

14. Rohrer JE, Arif AA, Pierce JR, Blackburn C: Unsafe Neighborhoods, Social Group Activity, and Self-Rated Health. J Public Health Manag Prac 2004, I 0: I 24- I 29.

I5. Parkerson GR, Broadhead WE, Tse C-KJ: The Duke Health Profile, A I7-Item Measure of Health and Dysfunction. Medical Care 1990, 28:1056-1072.

16. Parkerson GR, Broadhead WE, Tse CK: Validation of the Duke Social Support and Stress Scale. Family Medicine 1991, 23:357-60.

17. Denton M, Prus S, Walters V: Gender differences in health: a Canadian study of the psychosocial, structural and behavioral determinants of health. Social Science and Medicine 2004, 58:2585-2600.

18. Artazcoz L, Borrell C, Benach J: Gender indequalities in health among workers: the relation with family demands. J Epidemiol Community Health 200I, 55:639-647.

\section{Pre-publication history}

The pre-publication history for this paper can be accessed here: http://www.biomedcentral.com/1471-2296/5/11/prepub

\section{Publish with Bio Med Central and every scientist can read your work free of charge}

"BioMed Central will be the most significant development for disseminating the results of biomedical research in our lifetime. "

Sir Paul Nurse, Cancer Research UK

Your research papers will be:

- available free of charge to the entire biomedical community

- peer reviewed and published immediately upon acceptance

- cited in PubMed and archived on PubMed Central

- yours - you keep the copyright

Submit your manuscript here:

http://www.biomedcentral.com/info/publishing_adv.asp
BioMedcentral 